\title{
The role of different SIRT1-mediated signaling pathways in toxic injury
}

\author{
Zhihua Ren ${ }^{1 \dagger}$, Hongyi He ${ }^{1 \dagger}$, Zhicai Zuo ${ }^{1 \dagger}$, Zhiwen $\mathrm{Xu}^{1}$, Zhanyong Wei ${ }^{2^{*}}$ and Junliang Deng ${ }^{{ }^{*}}$
}

\author{
* Correspondence: weizhanyong@ \\ henau.edu.cn; dengj|213@126.com \\ ${ }^{\dagger}$ Zhihua Ren, Hongyi He and Zhicai \\ Zuo contributed equally to this \\ work. \\ ${ }^{2}$ The College of Animal Science and \\ Veterinary Medicine, Henan \\ Agricultural University, Zhengzhou \\ 450002, Henan Province, China \\ ${ }^{1}$ Key Laboratory of Animal Disease \\ and Human Health of Sichuan \\ Province, College of Veterinary \\ Medicine, Sichuan Agricultural \\ University, Chengdu 611130, \\ Sichuan Province, China
}

\begin{abstract}
Common environmental pollutants and drugs encountered in everyday life can cause toxic damage to the body through oxidative stress, inflammatory stimulation, induction of apoptosis, and inhibition of energy metabolism. Silent information regulator 1 (SIRT1), a nicotinamide adenine dinucleotide-dependent deacetylase, is a member of the evolutionarily highly conserved Sir2 (silent information regulator 2) superprotein family, which is located in the nucleus and cytoplasm. It can deacetylate protein substrates in various signal transduction pathways to regulate gene expression, cell apoptosis and senescence, participate in the process of neuroprotection, energy metabolism, inflammation and the oxidative stress response in living organisms, and plays an important role in toxic damage caused by toxicants and in the process of SIRT1 activator/inhibitor antagonized toxic damage. This review summarizes the role that SIRT1 plays in toxic damage caused by toxicants via its interactions with protein substrates in certain signaling pathways.
\end{abstract}

Keywords: SIRT1, Toxicant, SIRT1 activator, Signaling pathway

\section{Introduction}

Silent information regulator 1 (SIRT1) is a histone deacetylase of nicotinamide adenine dinucleotide $\left(\mathrm{NAD}^{+}\right)$, which mainly exists in the nucleus, and is a member of a family of well-studied mammalian sirtuins. SIRT1 interacts with protein substrates in a variety of signaling pathways (such as Wnt and Notch), participates in the regulation of most of the body's physiological functions, and plays a central regulatory role in cell proliferation, differentiation, senescence, apoptosis, and metabolism, attracting attention from researchers in various disciplines $[1,2]$.

In our daily life, we are constantly exposed to various sources of chemical and physical injury in the form of drugs, environmental pollutants, ultraviolet radiation, and ionizing radiation. At high levels, toxic substances can cause toxic damage through a variety of mechanisms including oxidative stress, inflammatory stimulation, and inhibition of energy metabolism, causing serious harm to the body [3]. Studies have shown that SIRT1 can participate in toxic damage caused by toxic substances by interacting with protein substrates, such as the Forkhead-box transcription factor (FOXO) family, nuclear factor kappa B (NF-kB), peroxisome proliferator-activated receptor gamma-assisted activating factor-1 (PGC-1), and tumor suppressor p53 in some signaling pathways [4-8]. It also plays an antagonistic role under the activation of SIRT1 activator. Therefore, this review will focus on the interaction between SIRT1 and protein substrates in some signaling

(c) The Author(s). 2019 Open Access This article is distributed under the terms of the Creative Commons Attribution 4.0 International License (http://creativecommons.org/licenses/by/4.0/), which permits unrestricted use, distribution, and reproduction in any medium, provided you give appropriate credit to the original author(s) and the source, provide a link to the Creative Commons license, and indicate if changes were made. The Creative Commons Public Domain Dedication waiver (http://creativecommons.org/ publicdomain/zero/1.0/) applies to the data made available in this article, unless otherwise stated. 
pathways to regulate the toxic damage process, providing a theoretical basis for further study of SIRT1.

\section{Pathway regulation of SIRT1 in toxicological damage}

SIRT1 can catalyze the deacetylation of acetyl lysine of histone substrate and some non-histone substrates to regulate gene expression. It can participate in the regulation of apoptosis, the inflammatory response, oxidative stress, energy metabolism, and other processes by regulating different pathways $[9,10]$, playing an important role in toxicological damage.

\section{SIRT1/PGC-1a}

PGC-1 $\alpha$ is a transcription factor co-activator that affects most cell metabolic pathways. It influences mitochondria respiration, the reactive oxygen species defense system, and fatty acid metabolism by interacting with specific transcription factors [11-13]. Studies have shown that SIRT1 can enhance tissue antioxidant capacity by activating the transcription of $\mathrm{PGC}-1 \alpha$ and inducing the expression of superoxide dismutase (SOD) and glutathione peroxidase (GSH-PX) in cells [14-16]. Therefore, when toxic substances directly act on SIRT1 to reduce its expression, it can reduce the antioxidant capacity of tissues and cause oxidative damage to the body. Yuan [4] found that early lead exposure could reduce phosphorylated PGC-1 $\alpha$ in the mouse cerebral cortex and SIRTl expression in the nucleus of cerebral cortex cells, increase the retention of PGC- $1 \alpha$ in the cytoplasm, reduce the activity of GSH-PX and the GSH content, and reduce the antioxidant capacity. Excessive fluoride can also inhibit SIRT1, significantly downregulate the protein expression level of SIRT1, and cause central nervous system oxidative damage through the SIRT1/PGC-1 $\alpha$ pathway [5]. SIRT1 can also regulate the function of PGC-1 $\alpha$ in cells by regulating the acetylation and activity level of PGC- $1 \alpha$, as well as regulation of downstream transcription factors such as nuclear receptor peroxisome proliferator-activated receptor (PPAR), estrogen-related receptor (ERR), nuclear respiratory factor (NRFs), and mitochondrial transcription factor A (Tfam), further affecting mitochondrial production and function [17, 18], and regulating the metabolism of glucose and lipids [19]. In addition, structural damage or dysfunction of mitochondria also leads to the initiation of apoptosis, so SIRT1 can regulate the functional state of mitochondria and indirectly control apoptosis by regulating the acetylation level of PGC-1 $\alpha$. Regarding cadmium toxicity damage, studies have found that cadmium treatment can obviously inhibit the expression of SIRT1 and increase PGC- $1 \alpha$ acetylation levels [8], damaging mitochondria and leading to mitochondrial dysfunction, and eventually inducing cell death processes such as apoptosis and necrosis [20-22], which may also be an important cause of hepatotoxicity induced by cadmium exposure. Valproic acid, an antiepileptic drug, also inhibits the protein expression level of SIRT1, causing hepatotoxicity [23] and mouse embryonic development abnormalities [24] through the SIRT1/PGC-1 $\alpha$ pathway. Therefore, in the toxic damage caused by some poisons, the SIRT1-mediated PGC-1 $\alpha$ pathway can play an important role by regulating the body's antioxidant capacity and mitochondrial production and functional status. 


\section{SIRT1/NF-KB}

$\mathrm{NF}-\mathrm{kB}$ is the master switch of the inflammatory response, which is usually connected to inhibitory protein inhibitor of NF-кB (ІкB) in the form of a p65/p50 dimer. When stimulated, p65/p50 can be activated and transferred to the nucleus to regulate the transcription of various downstream inflammatory factors $[25,26]$. The p65 subunit of $\mathrm{NF}-\mathrm{kB}$ is the direct target of SIRT1, which, through deacetylation, can control the acetylation level of NF- $\mathrm{kB}$ p 65 to regulate the transcription level of the downstream genes, including those encoding IL-1, tumor necrosis factor $\alpha$ (TNF- $\alpha$ ), IL-8, IL-6, and other inflammatory factors [27-31], thus regulating the inflammatory response. In addition, NF- $\mathrm{kB}$ is also involved in the regulation of apoptosis [32], and SIRT1 regulates anti-apoptosis-related gene expression through NF- $\mathrm{kB}$, such as inhibitor of apoptosis proteins (IAPs), the B-cell lymphoma-2 (Bcl-2) family, TNFR-associated factor (TRAF1, TRAF-2), JNK [33], etc., thereby controlling apoptosis. Regarding the toxic damage caused by fluorine, excessive fluoride can reduce the expression of SIRT1, so that NF- $\mathrm{kB}$ cannot be deacetylated, resulting in activation of the NF- $\mathrm{kB}$ signal, which causes neuronal apoptosis [34] and central nervous system damage [5, 35]. Studies have demonstrated that in an animal model of Alzheimer's disease, the $\beta$-amyloid protein (A $\beta)$ content in the brain is negatively correlated with the SIRT1 content in the same region $[36,37]$. SIRT1 attenuates the neurotoxic effects of $A \beta$ in Alzheimer's disease by inhibiting NF- $\mathrm{kB}$ signaling in microglia [28]. The antitumor antibiotic doxorubicin has serious side effects linked with cardiotoxicity [38]. Xi and coworkers [39] found that intraperitoneal injection of doxorubicin can lead to increased expression of malondialdehyde (MDA) and NF-KB protein, and decreased expression of SOD activity and SIRTl, causing oxidative stress and inflammatory damage in C57BL/6 J mice. It can be seen from the above that SIRT1 can regulate apoptosis by controlling the level of deacetylation of NF- $\mathrm{kB}$, thus affecting the toxic damage of some toxicants. However, the SIRT1/NF- $\mathrm{kB}$ pathway mainly participates in the toxic damage process of toxicants by the inflammatory response.

\section{SIRT1/FOXO}

The FOXO protein family is widely involved in cell signal transduction, growth and development, apoptosis, and antioxidant stress, among which FoxO1 and FoxO3 are the most common. This family of proteins can activate or inhibit a variety of target genes, such as p27kip1 and cyclin D (CCND) CYR61, which regulate the cell cycle, the bim and fasL genes that mediate apoptosis [40], TNF and tumor necrosis factor-related apoptosis-inducing ligand (TRAIL) [41], and the RAD51 gene involved in DNA damage repair.

The complex interaction between SIRT1 and FOXO protects against oxidative stress [42-44]. On the one hand, SIRT1 upregulates the deacetylation of FOXO, enhances FOXO-induced cell cycle arrest, activates and promotes the FOXO/MnSOD pathway, increases the expression of manganese superoxide dismutase (MnSOD) and catalase (CAT) to resist oxidative stress, and promotes the repair of DNA damage during replication $[45,46]$. On the other hand, after deacetylation of FOXO by SIRT1, FOXO can be degraded by ubiquitination, reducing the level of FOXO and inhibiting the ability of FOXO to induce cell death, thereby ultimately protecting cells from oxidative stress damage [47, 48]. In fluoride-induced central nervous system damage [5], 
doxorubicin-induced cardiotoxicity damage [49], and valproic acid-induced hepatotoxicity [23], the toxic effects on SIRT1 cause a decrease in expression, and a decrease in the level of FOXO deacetylation leads to an increase in apoptosis, leading to damage. Smoke from cigarettes has also been shown to cause oxidative stress damage in lung cells by acting on the SIRT1/FOXO pathway [50-52]. After activation of the SIRT1/ FOXO pathway, the level of FOXO deacetylation not only regulates the oxidative stress of the body, but also involves the control of cell apoptosis and the cell cycle, which is a complex and interactive process. Therefore, the study on the role of this pathway in the toxic injury of related toxins should be more comprehensive and systematic.

\section{SIRT1/Nrf2}

Nuclear factor E2-related factor 2 (Nrf2) is widely regarded as a transcription factor activated by oxidative stress that induces the coding of a series of antioxidant protective proteins and promotes the regulation of redox conditions in cells [53]. In addition, Nrf2 is also an important negative regulator of inflammatory cytokine activation and interleukin-1-mediated vascular inflammation [54,55], and therefore participates in the process of inflammation. Some studies have shown that Nrf2 can be regulated by acetylation [56, 57], while SIRTI can activate Nrf2 transcriptional activity and upregulate Nrf2 downstream gene expression of genes such as those encoding SOD and GSH [58, 59]. Conversely, downregulation of SIRT1 expression significantly reduced Nrf2 protein expression [60]. Regarding the toxic damage caused by paraquat, some studies have found that overexpression of SIRT1 can deacetylate NRF2, increase the stability of Nrf2, promote the transport of Nrf2 to the nucleus, promote the transcriptional activity of Nrf2, enhance the resistance of cells to oxidative damage, and play a protective role in the AEC-II injury of mice caused by paraquat poisoning [61, 62]. It can be seen that the SIRT1/Nrf2 pathway can antagonize the oxidative damage caused by some toxicants by enhancing the antioxidant capacity of the body.

\section{SIRT1/p53}

p53 can regulate the expression of a large number of downstream target genes, which in turn affects cell cycle organization, apoptosis, differentiation, and a number of other processes [63, 64]. SIRT1 enhances the expression of MnSOD by deacetylating p53, thereby increasing cellular antioxidant capacity $[65,66]$. It is also negatively regulated by 553 . When cells are under oxidative stress, SIRT1 can deacetylate the lysine residue at position 382 of the p53 protein and inhibit the activity of p53, thereby inhibiting the transcription of downstream target genes dependent on p53, such as CDKNIA and BAX, reducing cell apoptosis [67-69]. The p53-microRNA34a-SIRT1-p53 pathway has been shown to regulate the normal development and functioning of follicles [70]. In the process of reproductive damage caused by fluorosis, overexpression of SIRT1 can increase the levels of deacetylated p53, thereby antagonizing the reproductive damage caused by fluorosis and exerting a protective effect. In the toxic damage caused by some toxicants, SIRT1 can regulate the deacetylation level of p53, which can affect the antioxidant capacity of cells and regulate cell apoptosis. Gu et al. (2019) reported that SIRT1 plays an essential role in protection against fluoride-induced oxidative stress and 
mitochondria-dependent apoptosis in MC3T3-E1 cells. The SIRT1/p53/p21 pathway may be a potential therapeutic target for fluorosis [71].

To sum up, the substrates of SIRT1 action and corresponding biological function are summarized in Table 1. Figure 1 showing the role of different SIRT1-mediated signaling pathways in toxic injury.

\section{The role of SIRT1 agonists/inhibitors in toxic damage caused by toxicants}

To date, the most studied of the SIRT1 activators that antagonize toxic damage is resveratrol (Res). Res is a polyphenolic plant metabolite, and this family of metabolites were the first small molecule activators of SIRTl to be discovered [72]. Res is the most potent member of this family and can enhance the protein expression and activity of SIRTl $[73,74]$ and binds more easily to substrates following a change in the conformation of SIRTl $[75,76]$. Res can upregulate SIRTl and inhibit the production of reactive oxygen species through the SIRTl/FOXO3 pathway to resist oxidative damage [77]. Res can also regulate heme oxygenase 1 (HO-1) expression through the Nrf2/ARE signaling pathway to protect PCI2 cells from oxidative stress damage [78]. Anekonda and colleagues [79] found that Res could reduce the intracellular calcium level, downregulate Bax expression, upregulate the activity of SIRTl and Ku70, and inhibit the activity of caspase-3 and cell apoptosis.

In lead-induced toxic injury, Res can increase the level of SIRTl to deacetylate PGC-1a, increase the content of PGC-1a, activate the function of PGC-1a as an NRF-1 co-activator, bind DNA with NRF-1, enhance transcription and activate oxidative phosphorylation reactions [80], thereby inhibiting the formation of Ap (1-40) in the cerebral cortex of lead-exposed mice, protecting mice against lead exposure-induced problems with spatial learning and memory [81]. In addition, Res can also activate SIRT1 and increase MnSOD resistance to lead oxidative stress damage through mitochondrial biogenesis [82]. It has been found that in amphotericin-induced acute lung injury, Res can reduce the level of injury through multiple pathways, including inhibiting apoptosis, anti-oxidation, and protecting endothelial cells, and can upregulate SIRTl and reduce the subsequent production of inflammatory cytokines [83]. In a study by Sang and coworkers [84], it was found that Res may reduce the expression of the proapoptotic gene Bax by increasing expression of the SIRT1 gene and the anti-apoptotic gene BCL2, thereby exerting an anti-apoptotic effect and reducing the toxicity of zearalenone.

In addition to Res, melatonin can improve the functional status of mitochondria by promoting their production via the MT1/SIRT1/PGC-1 signaling pathway, thereby protecting against the hepatotoxicity caused by cadmium exposure [8]. SRT1720, a SIRT1

Table 1 Substrates of SIRT1 action and corresponding biological function

\begin{tabular}{ll}
\hline Substrate & Biological function \\
\hline PGC-1a & $\begin{array}{l}\text { Antioxidant stress, Regulate mitochondrial function and Regulating the } \\
\text { metabolism of glucose and lipid } \\
\text { NF-kB }\end{array}$ \\
Inhibition of inflammation, Regulation of apoptosis \\
NRF2 & Control of cell cycle, Antioxidant stress and Regulation of apoptosis \\
\hline
\end{tabular}




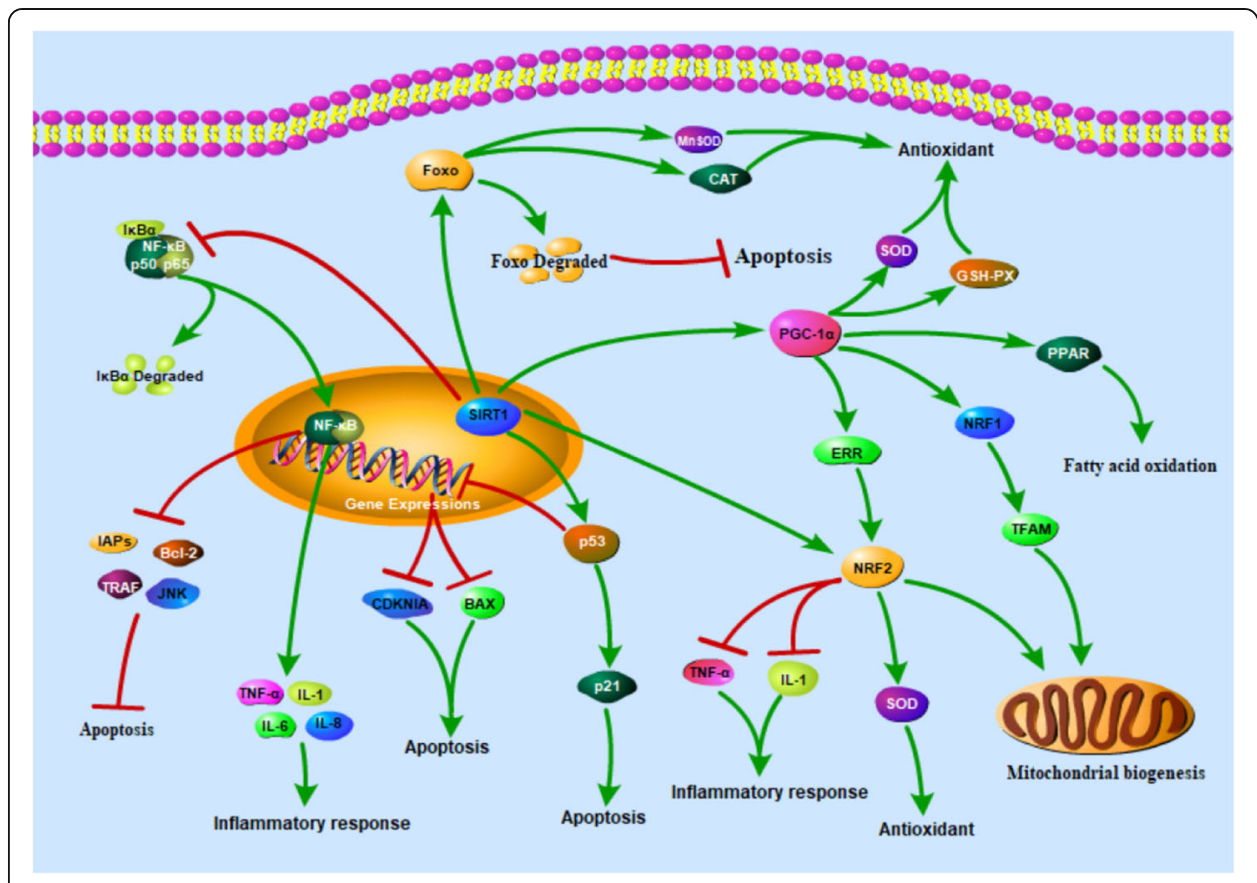

Fig. 1 The role of different SIRT1-mediated signaling pathways

specific activator, protected $\mathrm{H}_{2} \mathrm{O}_{2}$-induced senescent endothelium. It could protect against endothelial senescence and maintain cell function via the Akt/eNOS/VEGF axis [85]. SRT2104, also a SIRT1 specific activator, attenuated lipopolysaccharide-induced release of the cytokine interleukin-6 and inhibited activation of coagulation [86]. Rosuvastatin, a commonly used cardiovascular lipid-lowering drug, can upregulate the expression of SIRTl, further inhibiting the activity of NF- $\mathrm{kB}$, terminating the release of downstream inflammatory mediators, and protecting against doxorubicin-induced myocardial toxicity. In addition, salvianolic acid B (SaLB) can also activate the overexpression of SIRT1 [48]. Overexpression of SIRT1 can phosphorylate FOXO3a and lead to overexpression of MnSOD protein. MnSOD is an important antioxidant protein and a major antioxidant enzyme in mitochondria. It is mainly used to scavenge reactive oxygen species [87]. Therefore, SaLB can also protect against the cardiotoxicity caused by doxorubicin.

Although it can be found from most current studies that SIRT1 activators mainly play an antagonistic role in toxic damage caused by toxicants, some studies have reported that SIRT1 activators can aggravate toxic damage caused by toxicants, while SIRT1 inhibitors antagonize toxic damage caused by toxicants. Cai et al. [88] found that toxicity of extracellular $\mathrm{Zn}^{2+}$ depended on entry, elevation in intracellular free $\mathrm{Zn}^{2+}\left(\left[\mathrm{Zn}^{2+}\right] \mathrm{i}\right)$, a reduction in $\mathrm{NAD}^{+}$and ATP levels, and dysfunction of glycolysis and cellular metabolism. While SIRT proteins are $\mathrm{NAD}^{+}$-catabolic protein deacetylases, Res and fisetin can potentiate $\mathrm{NAD}^{+}$loss and $\mathrm{Zn}^{2+}$ neurotoxicity. In contrast, sirtinol, nicotinamide (NAM) and 2-hydroxynaphthaldehyde, inhibitors of the sirtuin pathway, attenuated both acute and chronic $\mathrm{Zn}^{2+}$ neurotoxicity. Lee et al. [89] found that NAM and sirtinol may alleviate high glucose/palmitate (HG/PA)-induced glucolipotoxicity to INS-1 beta cells by inhibiting the production of $\mathrm{NAD}^{+}$-depleting enzymes such as sirtuins. 
Table 2 The main role of each SIRT1 agonist/inhibitor in toxic damage caused by toxicants

\begin{tabular}{ll}
\hline SIRT1 modulators & Role in toxic damage caused by toxicants \\
\hline Res & $\begin{array}{l}\text { Antioxidant stress, Inhibits apoptosis, anti-inflammatory, } \\
\text { protect endothelial cells, potentiated NAD }{ }^{+} \text {loss }\end{array}$ \\
Melatonin & improve the functional status of mitochondria \\
SRT1720 & Protect endothelial cells \\
SRT2104 & Anti-inflammatory, inhibits activation of coagulation \\
Rosuvastatin & Anti-inflammatory \\
SaLB & Antioxidant stress \\
NAM & Prevents NAD Depletion \\
Sirtinol & Prevents NAD Depletion
\end{tabular}

Moreover, NAM prevents $\mathrm{NAD}^{+}$depletion and protects neurons against excitotoxicity and cerebral ischemia [90].

Finally, the main role of each SIRT1 agonist/inhibitor in toxic damage caused by toxicants are summarized in Table 2.

\section{Conclusion}

In summary, toxicant-induced injury affects SIRT1 expression, which then affects the expression and activity of downstream proteins, resulting in toxic damage. Upregulation of SIRT1 expression by SIRT1 activator can generally alleviate the toxicity of toxicants. SIRT1 can interact with proteins in various signal transduction pathways and regulate biological, physiological, and pathological processes. For example, SIRT1 can reduce the release of inflammatory factors by inhibiting the expression and activity of $\mathrm{NF}-\kappa \mathrm{B}$ in the NF- $\mathrm{B}$ signal transduction pathway, thus alleviating the inflammatory damage caused by some toxicants. Therefore, an in-depth study of the role and mechanism of action of SIRT1 in toxic damage caused by poisons may provide new insight into therapeutic strategies to limit the toxic damage caused by poisons.

\footnotetext{
Abbreviations

Aß: $\beta$-amyloid protein; BCl-2: B-cell lymphoma-2; CAT: Catalase; ERR: Estrogen-related receptor; GSH-PX: Glutathione peroxidase; HG/PA: High glucose/palmitate; HO-1: Heme oxygenase; IAPs: Inhibitor of apoptosis proteins; MDA: Malondialdehyde; MnSOD: Manganese superoxide dismutase; NAD: Nicotinamide adenine dinucleotide; NAM: Nicotinamid; NF-kB: Nuclear factor kappa B; Nrf2: Nuclear factor E2-related factor 2; NRFs: Nuclear respiratory factor; PGC-1: Peroxisome proliferator-activated receptor gamma-assisted activating factor-1; PPAR: Peroxisome proliferator-activated receptor; Res: Resveratrol; SaLB: Salvianolic acid B; SIRT1: Silent information regulator 1; SOD: Superoxide dismutase; Tfam: Mitochondrial transcription factors A; TNF-a: Tumor necrosis factor a; TRAIL: Tumor necrosis factor-related apoptosis-inducing ligand
}

\section{Acknowledgments}

The funders had no role in study design and interpretation, or the decision to submit the work for publication. We thank Kate Fox, DPhil, from Liwen Bianji, Edanz Group China (www.liwenbianji.cn/ac), for editing the English text of a draft of this manuscript.

\section{Funding}

The manuscript was supported by a national key research and development project (2016YFD050073) and a major science and technology project of Henan Province (141100110100).

\section{Availability of data and materials}

Not applicable

\section{Authors' contributions}

$\mathrm{RZH}$ carried out literature search and conceived the idea. HHY sorted out important background information and drafted the manuscript. ZZC and XZW critically revised the content of the manuscript. WZY and DJL performed the manuscript review. All authors read and approved the final manuscript. 
Ethics approval and consent to participate

Not applicable

\section{Consent for publication}

Not applicable

\section{Competing interests}

This article has not been published elsewhere in whole or in part. All authors have read and approved the content, and agree to submit for consideration for publication in the journal. The authors declared no conflict of interest. All work complies with the Ethical Policies of Cellular \& Molecular Biology Letters and has been conducted under internationally accepted ethical standards after relevant ethical review.

\section{Publisher's Note}

Springer Nature remains neutral with regard to jurisdictional claims in published maps and institutional affiliations.

Received: 22 March 2019 Accepted: 9 May 2019

Published online: 30 May 2019

\section{References}

1. Chang HC, Guarente L. SIRT1 and other sirtuins in metabolism. Trends Endocrinol Metab. 2014;25(3):138-45.

2. Chen YR, Lai YL, Lin SD, Li XT, Fu YC, Xu WC. SIRT1 interacts with metabolic transcriptional factors in the pancreas of insulin-resistant and calorie-restricted rats. Mol Biol Rep. 2013;40(4):3373-80.

3. Rahal A, Kumar A, Singh V, Yadav B, Tiwari R, Chakraborty S, Dhama K. Oxidative stress, Prooxidants, and antioxidants: the interplay. Biomed Res Int. 2014;2014:1-19.

4. Yuan W. Effects of resveratrol on oxidative stress in lead-induced AD-like lesions in mice. Zhengzhou Univ. 2014.

5. Chen D, Liu XH, Zeng XX, Gou QD, Xie C, Dong YT, et al. Expression of silencing information regulators in brain tissue of rats with chronic fluorosis and its relationship with learning and memory ability. Zhong Guo Di Fang Bing Xue Za Zhi. 2018;37(4):265.

6. Liu Y, Li YJ, Wang N, Liu ZH, Li HR, Liu YQ, et al. Expression of Sirtuin1 gene in brain tissues of fluorotoxic rats. Zhong Guo Di Fang Bing Xue Za Zhi. 2018;37(1):30-4.

7. Suzuki M, Bandoski C, Bartlett JD. Fluoride induces oxidative damage and SIRT1/autophagy through ROS-mediated JNK signaling. Free Radic Biol Med. 2015;89:369-78.

8. Guo P. Mechanism of melatonin protecting liver toxicity caused by cadmium exposure. Third Mil Med Univ. 2015

9. Hye SK, Malanie O. The ups and downs of SIRT1. Cell. 2008;9(8):1-9.

10. Li X, Zhang S, Blander G, Tse JG, Krieger M, Guarente L. SIRTI deacetylates and positively regulates the nuclear receptor LXR. Mol Cell. 2007;28(1):91-106.

11. Jones AWE, Yao Z, Vicencio JM, Wieckowska AK, Szabadkai G. PGC-1 family coactivators and cell fate: roles in cancer, neurodegeneration, cardiovascular disease and retrograde mitochondria-nucleus signaling. Mitochondrion. 2012;12(1):86-99.

12. Girnun GD. The diverse role of the PPARy coactivator 1 family of transcriptional coactivators in cancer. Seminars in cell \& developmental biology. Academic Press. 2012;23(4):381-8.

13. Lin J, Handschin C, Spiegelman BM. Metabolic control through the PGC-1 family of transcription coactivators. Cell Metab. 2005;1(6):361-70.

14. Basu S. A complex interplay between PGC-1 co-activators and mTORC1 regulates hematopoietic recovery following 5fluorouracil treatment. Stem Cell Res. 2014;12(1):178-93.

15. Curtil C, Enache LS, Radreau P, Dron AG, Scholtes C, Deloire A, et al. The metabolic sensors FXRa, PGC-1a, and SIRT1 cooperatively regulate hepatitis B virus transcription. The FASEB J. 2014;28(3):1454-63.

16. Cantó C, Auwerx J. PGC-1a, SIRT1 and AMPK, an energy sensing network that controls energy expenditure. Curr Opin Lipidol. 2009;20(2):98-105.

17. Patti ME, Butte AJ, Crunkhorn S, Cusi K, Berria R, Kashyap S, et al. Coordinated reduction of genes of oxidative metabolism in humans with insulin resistance and diabetes: potential role of PGC1 and NRF1. Proc Natl Acad Sci. 2003; 100(14):8466-71.

18. Mootha VK, Handschin C, Arlow D, Xie XH, Pierre JS, Sihag S, et al. Erra and Gabpa/b specify PGC-1a-dependent oxidative phosphorylation gene expression that is altered in diabetic muscle. Proc Natl Acad Sci. 2004;101(17):6570-5.

19. Rodgers JT, Lerin C, Haas W, Gygi SP, Spiegelman BM, Puigserver P. Nutrient control of glucose homeostasis through a complex of PGC-1a and SIRT1. Nature. 2005;434(7029):113.

20. Tang W, Shaikh ZA. Renal cortical mitochondrial dysfunction upon cadmium metallothionein administration to SpragueDawley rats. J Toxicol Environ Health A. 2001;63(3):221-35.

21. Wang JC, Zhu HL, Liu XZ, Liu ZP. N-acetylcysteine protects against cadmium-induced oxidative stress in rat hepatocytes. J Vet Sci. 2014;15(4):485.

22. Cannino G, Ferruggia E, Luparello C, Rinaldi AM. Cadmium and mitochondria. Mitochondrion. 2009;9(6):377-84.

23. Hou XY, Jin J, Li HL, Liu R, Fan XM, Huang M. The role of SIRT1 in the toxicity of valproic acid to hepatic cells. Chin Pharmacol Bull. 2015;31(1):31-4.

24. Di RF, Broccia ML, Giavini E, Menegola E. VPA-related axial skeletal defects and apoptosis: a proposed event cascade. Reprod Toxicol. 2010;29(1):106-12

25. Salminen A, Kauppinen A, Suuronen T, Kaarniranta K. SIRTI longevity factor suppresses NF-kB-driven immune responses: regulation of aging via NF-kB acetylation? BioEssays. 2008;30(10):939-42.

26. Nonn L, Duong D, Peehl DM. Chemo preventive anti-inflammatory activities of curcumin and other phytochemicals mediated by MAP kinase phosphatase-5 in prostate cells. Carcinogenesis. 2007;28(6):1188-96.

27. Zheng C, Yin Q, Wu H. Structural studies of NF-kB signaling. Cell Res. 2011;21(1):183. 
28. Yeung F, Hoberg JE, Ramsey CS, Keller MD, Jones DR, Frye RA, et al. Modulation of NF-KB-dependent transcription and cell survival by the SIRT1 deacetylase. The EMBO J. 2004;23(12):2369-80.

29. Guo R, Liu B, Wang K, Zhou SP, Li WM, Xu YW. Resveratrol ameliorates diabetic vascular inflammation and macrophage infiltration in db/db mice by inhibiting the NF-kB pathway. Diab Vasc Dis Res. 2014;11(2):92-102.

30. Hah YS, Cheon YH, Lim HS, Cho HY, Park BH, Ka SO, et al. Myeloid deletion of SIRT1 aggravates serum transfer arthritis in mice via nuclear factor-KB activation. PLoS One. 2014;9(2):e87733.

31. Rothgiesser KM, Erener S, Waibel S, Luscher B, Hottiger M. SIRT2 regulates NF-KB dependent gene expression through deacetylation of p65 Lys310. J Cell Sci. 2010;123(24):4251-8.

32. Panday A, Inda ME, Bagam P, Sahoo MK, Osorio D, Batra S. Transcription factor NF-KB: an update on intervention strategies. Arch Immunol Ther Exp. 2016;64(6):463-83.

33. Gu X, Han D, Chen W, Zhang L, Lin Q, Gao J, et al. SIRT1-mediated FoxOs pathways protect against apoptosis by promoting autophagy in osteoblast-like MC3T3-E1 cells exposed to sodium fluoride. Oncotarget. 2016;7(40):65218-30.

34. Kopitar JN. Innate immune response in brain. NF-kappa B signaling and cystatins Front Mol Neurosci. 2015;8:73.

35. Tang T, Wen YU, Guan Z. Enhanced expression of inflammatory cytokines and nuclear factor-kB in microglia by overdose fluoride. Zhong Guo Di Fang Bing Xue Za Zhi. 2015;34(11):785-9.

36. Kim D, Nguyen MD, Dobbin MM, Fischer A, Sananbenesi F, Rodgers JT, et al. SIRT1 deacetylase protects against neurodegeneration in models for Alzheimer's disease and amyotrophic lateral sclerosis. The EMBO J. 2007;26(13):3169-79.

37. Qin W, Chachich M, Lane M, Roth G, Bryant M, De CR, et al. Calorie restriction attenuates Alzheimer'S disease type brain amyloidosis in squirrel monkeys (Saimiri sciureus). J Alzheimers Dis. 2006;10(4):417-22.

38. Garwood ER, Kumar AS, Baehner FL, Moore DH, Au A, Hylton N, et al. Fluvastatin reduces proliferation and increases apoptosis in women with high grade breast cancer. Breast Cancer Res Treat. 2010;119(1):137-44.

39. Xi ZC. Reversal of Sirt1/NF-kB signaling pathway by rosuvastatin inhibits myocardial injury in adriamycin; 2015 .

40. Yang JY, Chang CJ, Xia W, Wang Y, Wong KK, Engelman JA, et al. Activation of FOXO3a is sufficient to reverse mitogenactivated protein/extracellular signal-regulated kinase kinase inhibitor chemoresistance in human cancer. Cancer Res. 2010;70:4709-18.

41. Wiley SR, Schooley K, Smolak PJ, Din WS, Huang CP, Nicholl JK, et al. Identification and characterization of a new member of the TNF family that induces apoptosis. Immunity. 1995;3(6):673-82.

42. Maiese K, Chong ZZ, Shang YC. "Sly as a FOXO": new paths with Forkhead signaling in the brain. Curr Neurovasc Res. 2007:4(4):295-302

43. Maiese K, Chong ZZ, Shang YC. OutFOXOing disease and disability: the therapeutic potential of targeting FoxO proteins. Trends Mol Med. 2008;14(5):219-27.

44. Hwang J, Rajendrasozhan S, Yao HW, Chung S, Sundar IK, Huyck HL, et al. FOXO3 deficiency leads to increased susceptibility to cigarette smoke-induced inflammation, airspace enlargement, and chronic obstructive pulmonary disease. The J Immunol. 2011. https://doi.org/10.4049/jimmunol.1001861.

45. Xie H, Hou S, Jiang J, Sekutowicz M, Kelly J, Bacskai BJ. Rapid cell death is preceded by amyloid plaque-mediated oxidative stress. Proc Natl Acad Sci. 2013;110(19):7904-9.

46. Brunet A, Sweeney LB, Sturgill JF, Chua KF, Greer PL, Lin YX, et al. Stress-dependent regulation of FOXO transcription factors by the SIRT1 deacetylase. Science. 2004;303(5666):2011-5.

47. Wang YQ, Cao Q, Wang F, Huang LY, Sang TT, Liu F, et al. SIRT1 protects against oxidative stress-induced endothelial progenitor cells apoptosis by inhibiting FOXO3a via FOXO3a ubiquitination and degradation. J Cell Physiol. 2015;230(9):2098-107.

48. Giannakou ME, Partridge L. The interaction between FOXO and SIRT1: tipping the balance towards survival. Trends Cell Biol. 2004;14(8):408-12.

49. Huang L. Protective effect of SalB on adriamycin-induced cardiotoxicity and its mechanism; 2015

50. Yao H, Hwang J, Sundar IK, Friedman AE, Mcburney MW, Guarente L, et al. SIRT1 redresses the imbalance of tissue inhibitor of matrix metalloproteinase-1 and matrix metalloproteinase-9 in the development of mouse emphysema and human COPD. Am J Physiol Lung Cell Mol Physiol. 2013;305(9):615-24.

51. Yao H, Sundar IK, Huang Y, Gerloff J, Sellix MT, Sime PJ, et al. Disruption of SIRT1-mediated control of circadian molecular clock and inflammation in chronic obstructive pulmonary disease. Am J Respir Cell Mol Biol. 2015;53(6):782-92.

52. Hwang JW, Sundar IK, Yao H, Sellix MT, Rahman I. Circadian clock function is disrupted by environmental tobacco/ cigarette smoke, leading to lung inflammation and injury via a SIRT1-BMAL1 pathway. The FASEB J. 2014;28(1):176-94.

53. Rushmore TH, Morton MR, Pickett CB. The antioxidant responsive element. Activation by oxidative stress and identification of the DNA consensus sequence required for functional activity. J Biol Chem. 1991;266(18):11632-9.

54. Freigang S, Ampenberger F, Spohn G, Heer S, Shamshiev AT, Kisielow J, et al. Nrf2 is essential for cholesterol crystalinduced inflammasome activation and exacerbation of atherosclerosis. Eur J Immunol. 2011;41(7):2040-51.

55. Bancos S, Baglole CJ, Rahman I, Phipps RP. Induction of heme oxygenase-1 in normal and malignant B lymphocytes by 15-deoxy-Delta (12, 14)-prostaglandin J (2) requires Nrf2. Cell Immunol. 2010;262(1):18-27.

56. Sun Z, Chin YE, Zhang DD. Acetylation of Nrf2 by p300/CBP augments promoter-specific DNA binding of Nrf2 during the antioxidant response. Mol Cell Biol. 2009;29(10):2658-72.

57. Kawai Y, Gardufio LK, Theodore M, Yang J, Arinze IJ. Acetylation — deacetylation of the transcription factor Nrf2(nuclear factor erythroid 2-related factor 2) regulates its transcriptional activity and nucleocytoplasmic localization. J Biol Chem. 2011;286(9):7629-40

58. Huang K, Chen C, Hao J, Huang J, Wang S, Liu P, et al. Polydatin promotes Nrf2-ARE anti-oxidative pathway through activating Sirt1 to resist AGEs-induced upregulation of fibronetin and transforming growth factor- $\beta 1$ in rat glomerular messangial cells. Mol Cell Endocrinol. 2015;399:178-89.

59. Huang K, Huang J, Xie X, Wang S, Chen C, Shen X, et al. Sirt1 resists advanced glycation end products-induced expressions of fibronectin and TGF- $\beta 1$ by activating the Nrf2/ARE pathway in glomerular mesangial cells. Free Radic Biol Med. 2013;65:528-40.

60. Lu H, Chang Z, Han W, Wang L, Hong G. Curcumin reduces paraquat-induced oxidative injury in A549 cells by activation of the Nrf2-ARE pathway. Zhonghua Lao Dong Wei Sheng Zhi Ye Bing Za Zhi. 2014;32(1):44-9.

61. Ding YW. Protective effect of SIRT1/NRF2 signaling pathway on mouse type II alveolar epithelial cells treated with paraquat; 2016. 
62. Li SQ. Role of signaling pathway SIRT1/NRF2 in lung injury induced by paraquat poisoning mice and intervention of resveratrol; 2014.

63. Vousden KH, Lu X. Live or let die: the cell's response to p53. Nat Rev Cancer. 2002;2(8):594.

64. Laptenko O, Prives C. Transeriptional regulation by p53: one protein, many possibilities. Cell Death Differ. 2006;13(6): 951-61.

65. Gonfloni S, lannizzotto V, Maiani E, Bellusci G, Ciccone S, Diederich M. P53 and Sirt1: routes of metabolism and genome stability. Biochem Pharmacol. 2014;92(1):149-56.

66. Cheng $Y$, Takeuchi $H$, Sonobe $Y$, Jin $S$, Wang $Y$, Horiuchi $H$, et al. Sirtuin 1 attenuates oxidative stress via upregulation of superoxide dismutase 2 and catalase in astrocytes. J Neuroimmunol. 2014;269(1-2):38-43.

67. Vaziri H, Dessain SK, Eaton EN, Imai SI, Frye RA, Pandita TK, et al. hSIR2(SIRT1) functions as an NAD-dependent p53 deacetylase. Cell. 2001;107(2):149-59.

68. Luo J, Nikolaev AY, Imai S, Chen D, Su F, Shiloh A, et al. Negative control of p53 by Sir2a promotes cell survival under stress. Cell. 2001;107(2):137-48.

69. Rahman S, Islam R. Mammalian Sirt1: insights on its biological functions. Cell Commun Signal. 2011;9(1):11.

70. Castro RE, Ferreira DMS, Afonso MB, Borralho PM, Machado MV, Pinto HC, et al. miR-34a/SIRT1/p53 is suppressed by ursodeoxycholic acid in the rat liver and activated by disease severity in human non-alcoholic fatty liver disease. J Hepatol. 2013:58(1):119-25.

71. Gu X, Wang Z, Gao J, Han D, Zhang L, Chen P, et al. SIRT1 suppresses p53-dependent apoptosis by modulation of p21 in osteoblast-like MC3T3-E1 cells exposed to fluoride. Toxicol in Vitro. 2019;57:28-38.

72. Kwon It S, Ott M. The ups and downs of SIRTI. Trends Biochem Sci. 2008;33(11):517-25.

73. Pacholec M, Bleasdale JE, Chrunyk B, Cunningham D, Flynn D, Garofalo RS, et al. SRTI 720, SRT2 183, SRTI460, and resveratrol are not direct activators of SIRTI. J Biol Chem. 2010;285(11):8340-5I.

74. Tennen Rl, Michishita KE, Chua KF. Finding a target for resveratrol. Cell. 2012;148(3):387-9.

75. Kim EJ, Kho JH, Kang MR, Um SJ. Active regulator of SIRTI cooperates with SIRTI and facilitates suppression of p53 activity. Mol Cell. 2007;28(2):277-90.

76. Borra MT, Smith BC, Denu JM. Mechanism of human SIRT1 activation by resveratrol. J Biol Chem. 2005:280(17):187-95.

77. Yun JM, Chien A, Jialal I, Devaraj S. Resveratrol up_regulates SIRTI and inhibits cellular oxidative stress in the diabetic milieu:mechanistic insights. J Nutrition Biochem. 2012;23(7):699-705.

78. Chen CY, Jang JH, Li MH, Surh YJ. Resveratrol upregulates heme oxygenase-l expression via activation of NF-E2-related factor 2 in PCI2 cells. Biochem Biophys Res Commun. 2005;331(4):993-1000

79. Anekonda TS, Adamus G. Resveratrol prevents antibody-induced apoptotic death of retinal cells through upregulation of Sirt1 and Ku70. BMC Res Notes. 2008;1(1):122.

80. Koo SH, Montminy M. In vino veritas: a tale of two sirt1s. Cell. 2006;127(6):1091-3.

81. Sun AY, Wang Q, Simonyi A, Sun GY. Resveratrol as a therapeutic agent for neurodegenerative diseases. Mol Neurobiol. 2010;41(2-3):375-83.

82. Li Y, Zhu W, Tao J, Xin P, Liu M, Li J, et al. Resveratrol protects cardiomyocytes from oxidative stress through SIRTI and mitochondrial biogenesis signaling pathways. Biochem Biophys Res Commun. 2013:438(2):270-6.

83. Rieder SA, Nagarkatti P, Nagarkatti M. Multiple anti-inflammatory pathways triggered by resveratrol lead to amelioration of staphylococcal enterotoxin Binduced lung injury. Br J Pharmacol. 2012;167(6):1244-58.

84. Sang YQ, Zhang GY, Li WZ. Interference effects of resveratrol on cytotoxicity of human embryonic kidney HEK293 induced by zearalenone. Xiandai Shipin Keji. 2016;10:1-8.

85. Li RL, Lu ZY, Huang JJ, Qi J, Hu A, Su ZX, et al. SRT1720, a SIRT1 specific activator, protected H2O2-induced senescent endothelium. Am J Transl Res. 2016;8(7):2876-88.

86. Vand MAJ, Scicluna BP, Moerland PD, Lin J, Jacobson EW, Vlasuk GP, et al. The selective Sirtuin 1 activator SRT2104 reduces endotoxin-induced cytokine release and coagulation activation in humans*. Crit Care Med. 2015;43(6):e199-202.

87. Deng $T$, Li J, Ma G, Wang X, Zhao X, Zhang F, et al. Identification of the function of superoxide dismutase gene from Dunaliella salina in SOD deleted strain K12. Sichuan Da Xue Xue Bao Zi Ran Ke Xue Ban. 2007;1 (44):176-80.

88. Cai AL, Zipfel GJ, Sheline CT. Zinc neurotoxicity is dependent on intracellular NAD levels and the sirtuin pathway. Eur J Neurosci. 2006;24(8):2169-76.

89. Lee SJ, Choi SE, Jung IR, Lee KW, Kang Y. Protective effect of nicotinamide on high glucose/palmitate-induced glucolipotoxicity to INS-1 beta cells is attributed to its inhibitory activity to sirtuins. Arch Biochem Biophys. 2013;535(2): 187-96.

90. Liu D, Gharavi R, Pitta M, Gleichmann M, Mattson MP. Nicotinamide prevents NAD depletion and protects neurons against excitotoxicity and cerebral ischemia: NAD ${ }^{+}$consumption by SIRT1 may endanger energetically compromised neurons. NeuroMolecular Med. 2009;11(1):28-42.

\section{Ready to submit your research? Choose BMC and benefit from:}

- fast, convenient online submission

- thorough peer review by experienced researchers in your field

- rapid publication on acceptance

- support for research data, including large and complex data types

- gold Open Access which fosters wider collaboration and increased citations

- maximum visibility for your research: over $100 \mathrm{M}$ website views per year

At $\mathrm{BMC}$, research is always in progress.

Learn more biomedcentral.com/submissions 